\title{
Removal of Melachite Green Dye by Using Zinc Oxide Nanoparticles Prepared by The Green Synthesis by Using Camellia Sinensis (Green Tea) Leafs Extract
}

\author{
Madiha Batool ${ }^{1 *}$, Zahid Qureshi ${ }^{1}$ and Aliya Basir ${ }^{3}$ \\ ${ }^{1}$ Department of Chemistry, Government College University, Pakistan \\ ${ }^{2}$ PGIC cooper road Lahore, Pakistan
}

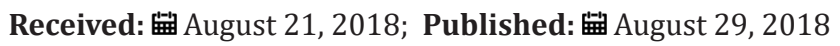

*Corresponding author: Madiha Batool, Department of Chemistry, Government College University, Lahore, Pakistan

\begin{abstract}
Green synthesis for nanoparticles using microorganisms, enzymes, and plants leaf or plant extracts have been indicated as possible ecofriendly preferences to chemical and physical methods. In this paper, we report the synthesis of zinc oxide particles by green method. Highly stable and hexagonal zinc oxide nanoparticles were produced by using zinc nitrate and green tea leaf extract. Structural, morphological and optical properties of the synthesized nanoparticles have been characterized by using UV-Vis spectrophotometer, FTIR, SEM, and XRD analysis. The synthesis of nanoparticles of zinc oxide was observed by the color changing of the chemical solution. Powder X-ray diffraction and SEM analysis revealed the synthesis of both $\mathrm{Zn}$ and $\mathrm{ZnO}$ nanoparticles with average particle size of $60 \mathrm{~nm}$. Shape of zinc oxide nanoparticles was hexagonal with the range $80-120 \mathrm{~nm}$. UV spectra confirmed the presence of zinc oxide nanoparticles. FTIR showed the peaks of zinc oxide nanoparticles as well as the presence of other compounds. Melachite green dye has been removed by using zinc oxide nanoparticles prepared from green tea leaf extract. The green color of the dye was removed up to $70 \%$ with the use of reducing agent sodium borohydrate. Removal of melachite green dye was performed. Other applications of zinc oxide nanoparticles in the medicine, pharma, biotechnology and industries were discussed.
\end{abstract}

Keywords: Green Tea Leaf Extract; SEM; Zinc Oxide Nanoparticles; Green Synthesis; XRD

\section{Introduction}

Nanotechnology literally means any technology on a nanoscale. Nanotechnology encloses the yeild and application of physical, chemical, and biological systems at scales ranging from individual atoms or molecules to submicron dimensions, as well as the involvement of the nanostructures that are formed into the larger systems. Nanotechnology continue to move forward in making the fabrication of micro/nanodevices and systems possible for a variety of industrial, consumer, and biomedical applications also used in various fields like drugs and medicines, electronics, food, fuel cells, solar cells, batteries, in space, chemical censors and fabric etc [1]. The biosynthesis of nanoparticles has been proposed as a cost-effective and environmentally friendly alternative to chemical and physical methods. Plant-mediated synthesis of nanoparticles is a green chemistry approach that connects nanotechnology with plants. Green synthesis has been involved in synthesis of highly stabilized nanoparticles. Nanoparticles integrity maintenance is the challenge by green synthesis. Zinc oxide nanoparticles have been synthesized by leaf extract of green tea. It is a common name of Chinese white [2]. The green synthesis of zinc oxide nanoparticle is fast, economically feasible, and sufficient method. Phenolic content in plant extract which dissolves in water, biodegradable and catalyze synthesis of nanoparticle as capping and reducing agent [3].

Green tea was used as a medicine India as well as in Chinese medicine. Green tea ensures better health and longevity. Recent studies have also shown green tea can potentially have positive effects on everything from weight loss to liver disorders, type 2 diabetes, and Alzheimer disease. Unsweetened green tea is totally 
contains $0 \%$ calorie in it. The amount of caffeine in a cup of tea can changes according to the length of insinuate time and the amount of tea. Basically, green tea contains a moderately small amount of caffeine. Almost 20-45mg per 8-ounce cup is present in it. Green tea is one of the world's healthiest drinks that contains one of the greatest amounts of antioxidants of any tea. Natural chemicals such as polyphenols in tea provides its anti-inflammatory and anticarcinogenic effects. Green tea has almost $20-45 \%$ polyphenols by weight, in which $60-80 \%$ are catechins such as EGCG. Catechins are antioxidants and helps to prevent cell damage [4] (Figures 1 \& 2).

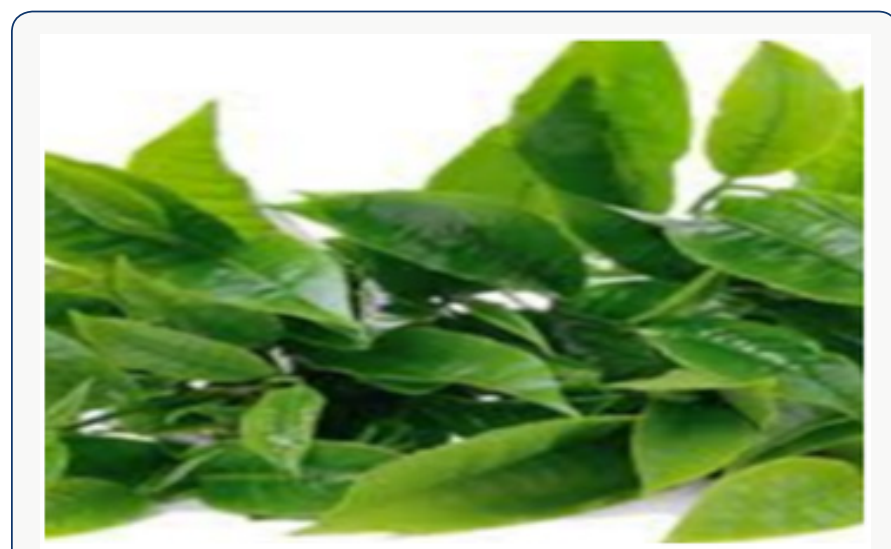

Figure 1: Green tea leaf.

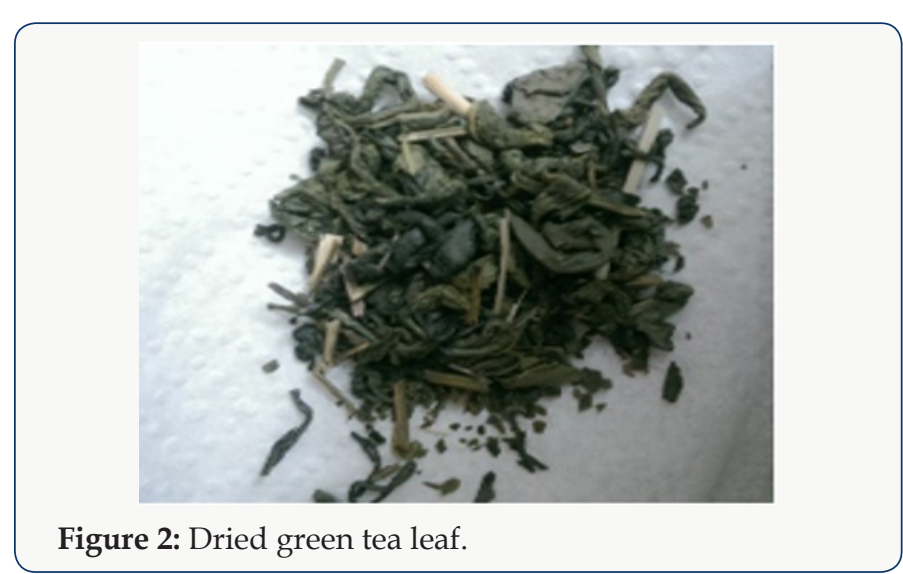

Material and Method

\section{Material}

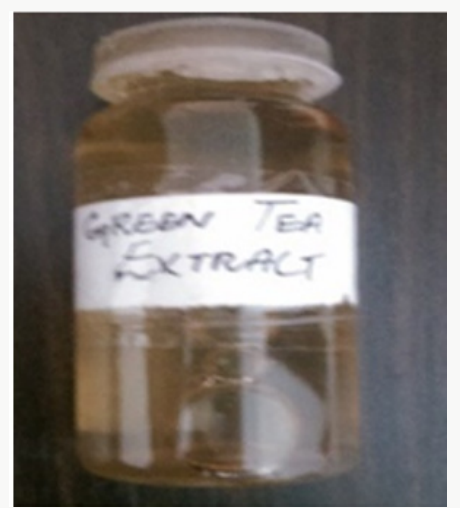

Figure 3: Green tea leaf extract.
Green tea leaf was collected from garden, zinc nitrate salt, distilled water, sodium borohydrate, oxalic acid, methanol. Glassware which was used included beaker, stirrer, test tubes, funnel. Other apparatus included thermostat and hotplate [5] (Figure 3).

\section{GREEN Synthesis of ZnO NPs}

zinc nitrate solution of fifty milliliter was added to $5 \mathrm{ml}$ of green tea leaf extract. The solution was stirred on magnetic stirrer at 120 degrees [6]. The color change was observed from light brown to blackish brown. The resultant solution was centrifuged for ten minutes at speed of 50,000rpm. After discarding suspended zinc oxide nanoparticles were dried in watch glass. Yellow colored particles were collected for characterization [7] (Figures 4 \& 5).

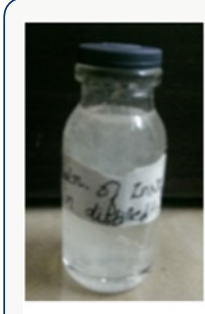

(a)

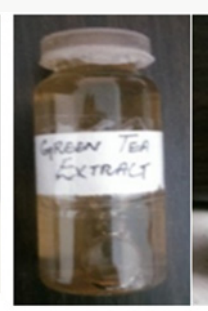

(b)

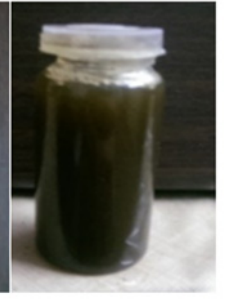

(c)

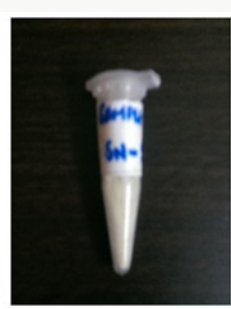

(d)
Figure 4: (a)salt soln. of zinc nitrate, (b) green tea leaf extract, (c) soln. containing nanoparticles (d) yellow colored zinc oxide nanoparticles.

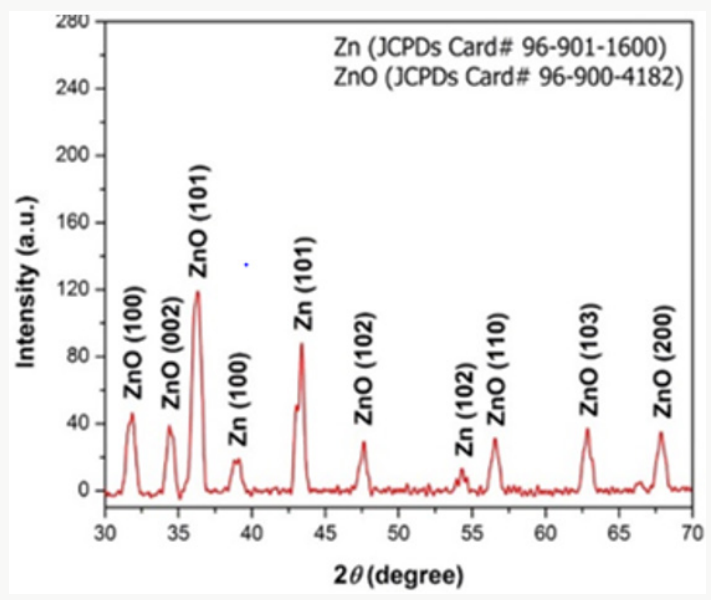

Figure 5: XRD of zinc and zinc oxide nanoparticles.

\section{Characterization Techniques of Green Synthesis Zinc Oxide Nanoparticles}

Structural, chemical composition, size and shape of zinc oxide nanoparticles were analyzed by SEM(JSM-6480LM), XRD (XPERTPRO), TEM, and UV spectrophotometer (DB-20).

Results

\section{Color Change Observation}

When the mixture of salt zinc nitrate and green tea leaf extract was added and heat the color changes appeared. Color changes 
indicate the formation of nanoparticles of zinc oxide. Brown color solution was turned into blackish brown indicated for formation of zinc oxide nanoparticles synthesis as in Figure 6 [8].

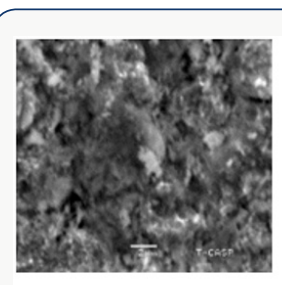

(a)

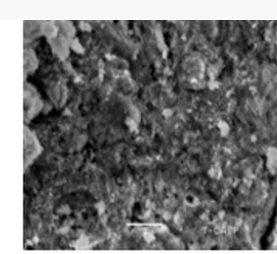

(b)

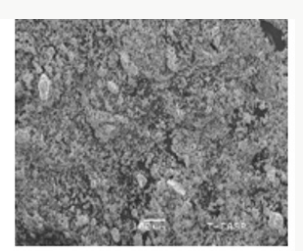

(c)
Figure 6: SEM images at different magnifications (a) 2um (b) 5 um (c) 100um.

\section{X-Rays Diffraction Studies}

This technique basically tells us about the crystal density, purity and size of the metal nanoparticle prepared. Zinc oxide nanoparticles were examined by X-ray diffractometer (XPERTPRO). Zinc oxide powder was put in cubes of XRD for calculation of intensity. The resultant pattern of synthesized zinc oxide nanoparticles was analyzed [10]. The peaks at $2 \theta$ correspond to intensity as $31.75,34.4,36.25,47.56 .55,62.80,66.388,67.9,69.0$, 72.6, 76.9, 81.40, 89.63.0, 92.77, 95.3, 98.6, 102.9, 104.1, 107.4, $110.3,116.2,121.5,125.2,133.97,136.6,138.5,142.9$ and have $100,101,100,101,102,102,110$ and 103 patterns compare to JCPDS card of numbers 96-901-1600 of zinc and 96-900-4282 of ZnO. The mineral name is zincite. Its common name is Chinese white. The space group is 186 .the calculated density was $5.68 \mathrm{~g} /$ $\mathrm{cm}^{3}$.and measured density was $5.66 \mathrm{~g} / \mathrm{cm}^{3} .<0.001 \%$ of each $\mathrm{Mg}, \mathrm{Si}$, $\mathrm{Ca}$ were present. The temperature at which we collected data was $26^{\circ} \mathrm{C}$ (Figure 7).

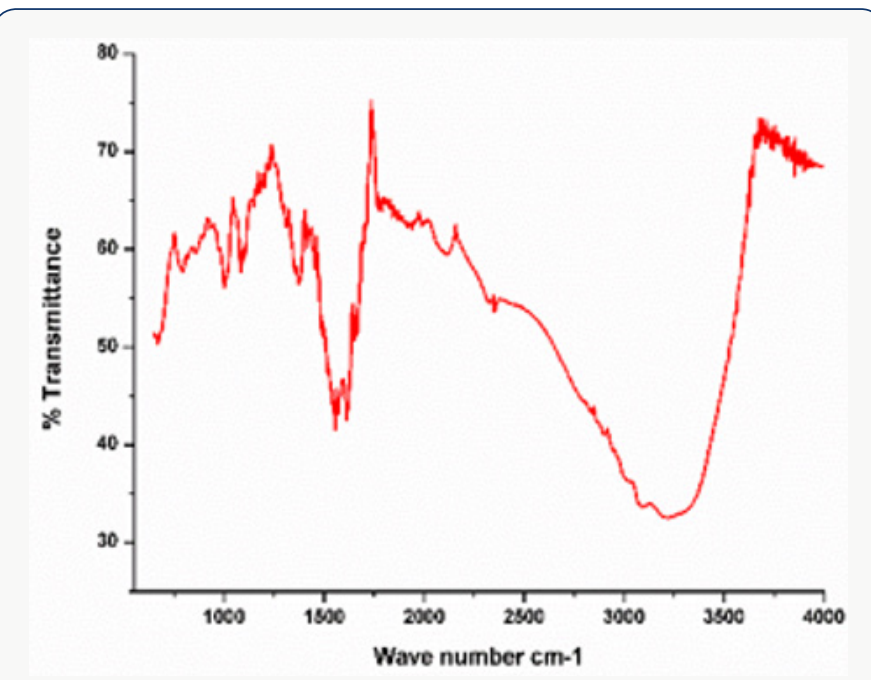

Figure 7: FTIR spectra of zinc oxide nanoparticles.

\section{Scanning Electron Microscope (Sem)}

This technique tells us about the particle size of metallic nanoparticles. Average particle size of zinc oxide nanoparticle was analyzed by SEM model (JSM-6480LM). The zinc oxide nanoparticle SEM micrograph were calculated about $\mathrm{nm}$. It was observed that partials were smooth with hexagonal shape. EDX result showed strong zinc oxide signal with other elements too like carbon, phosphorus (Figure 8).

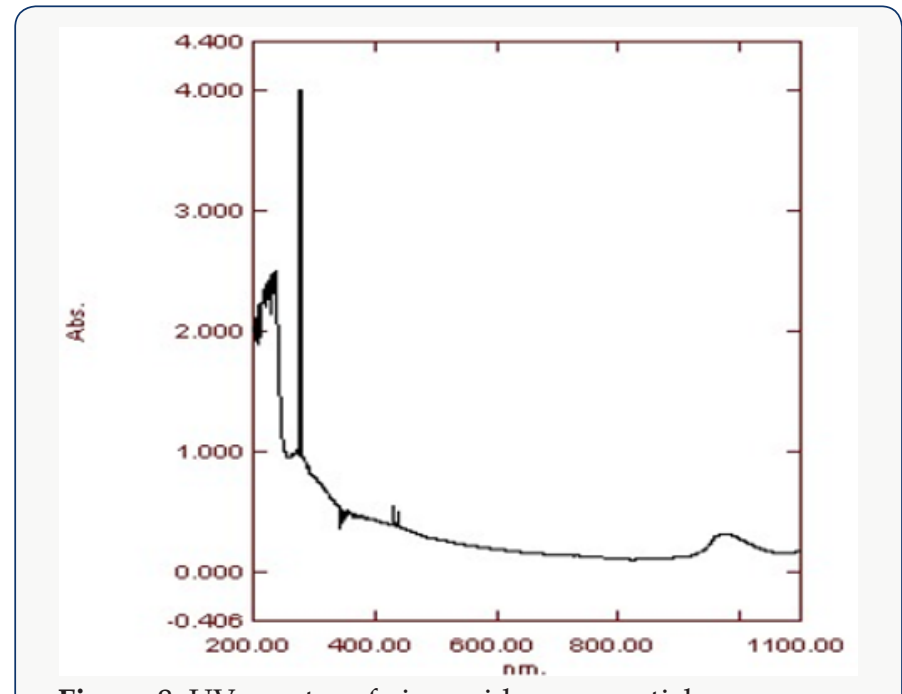

Figure 8: UV spectra of zinc oxide nanoparticles.

\section{FTIR Analysis}

In this study FTIR spectrum was analyzed to confirm zinc oxide nanoparticles. Peaks were observed at $457 \mathrm{~cm}^{-1}$ and $545 \mathrm{~cm}^{-}$ ${ }^{1}$ shows that zinc oxide nanoparticles are present. Other peaks indicate presence of other groups. $\mathrm{OH}$, stretch of hydrogen group gives peak at $3215.08 \mathrm{~cm}^{-1}$. Methoxy methyl ether $\mathrm{CH}$ stretch gives peak at $2964.17 \mathrm{~cm}^{-1}$. Alkenyl C=C stretch is present at $1636.68 \mathrm{~cm}^{-}$ 1 . Amine NH bend gives peak at $1541.82 \mathrm{~cm}^{-1}$. Aromatic phosphate $\mathrm{P}-\mathrm{O}-\mathrm{C}$ stretch at $1240.07 \mathrm{~cm}^{-1}$ is present in Figure 9.

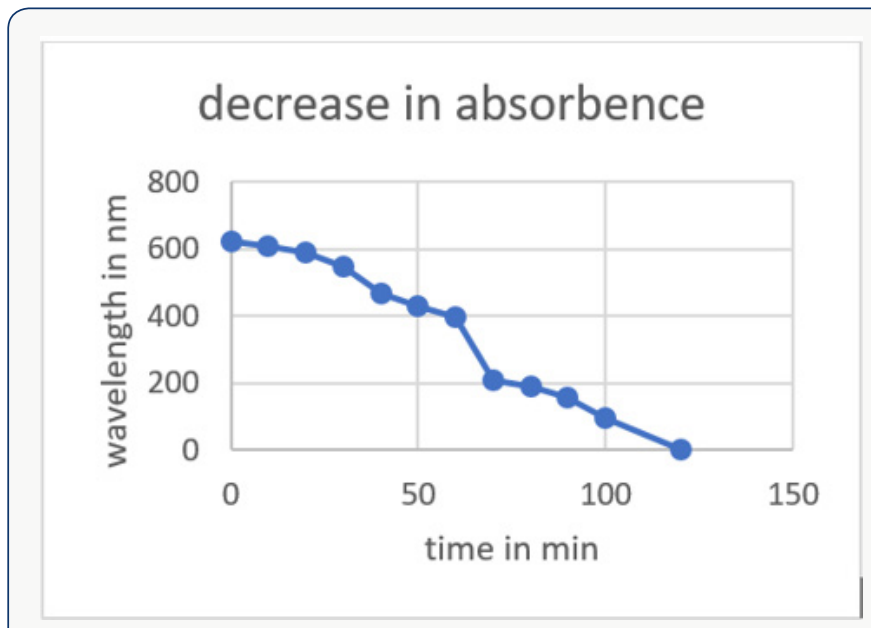

Figure 9: Graph of decrease in absorbance with increase in time.

\section{UV Visible Spectra}

UV gives us the wavelength range of metal nanoparticles. The highest peak shows the maximum absorbance. Absorption peaks of UV spectrometer at range of $300-400 \mathrm{~nm}$ confirm the formation 
of zinc oxide nanoparticles. The main advantage of this procedure is that it is easily available, non-costly and is easy to handle. As the sample used is non-toxic thus is pollution free. The nanoparticles prepared have been used in various industries of medicine, pharma, biochemistry and fabric etc [10] (Figure 10) and (Table 1).

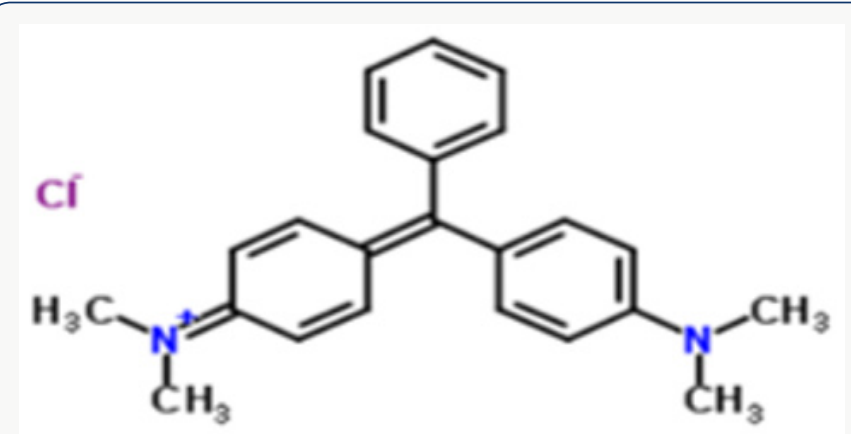

Figure 10: Chemical structure of melachite green.

Table 1.

\begin{tabular}{|c|c|c|}
\hline Groups & $\begin{array}{c}\text { Stretching or } \\
\text { Bending }\end{array}$ & Ranges \\
\hline $\mathrm{ZnO}$ & & $457-545 \mathrm{~cm}^{-1}$ \\
\hline $\mathrm{C}=\mathrm{C}$ & stretch & $1636.68 \mathrm{~cm}^{-1}$ \\
\hline $\mathrm{NH}$ & bend & $1541.82 \mathrm{~cm}^{-1}$ \\
\hline $\mathrm{OH}$ & stretch & $3215.08 \mathrm{~cm}^{-1}$ \\
\hline $\mathrm{CH}$ & bend & $2964.17 \mathrm{~cm}^{-1}$ \\
\hline $\mathrm{CI}$ & stretch & $540.91 \mathrm{~cm}^{-1}$ \\
\hline
\end{tabular}

\section{Dye Removal by Zno Nanoparticles}

$1 \mathrm{mg}$ of zinc oxide nanoparticles were taken then using $20 \mathrm{mg}$ of dye solution we add those $\mathrm{ZnO}$ nanoparticles. $0.1 \mathrm{mg}$ of sodium borohydrate was added as a reducing agent. The color began to fade. Firstly, the peak of melachite green was noted in UV that was $621 \mathrm{~nm}$. On color changes the peaks were noted in the UV spectrophotometer with specific time intervals. The wavelength begins to decrease from $621 \mathrm{~nm}$. After the color has almost fade out the peak was noted that was $0 \mathrm{~nm}$ (Figure 11).

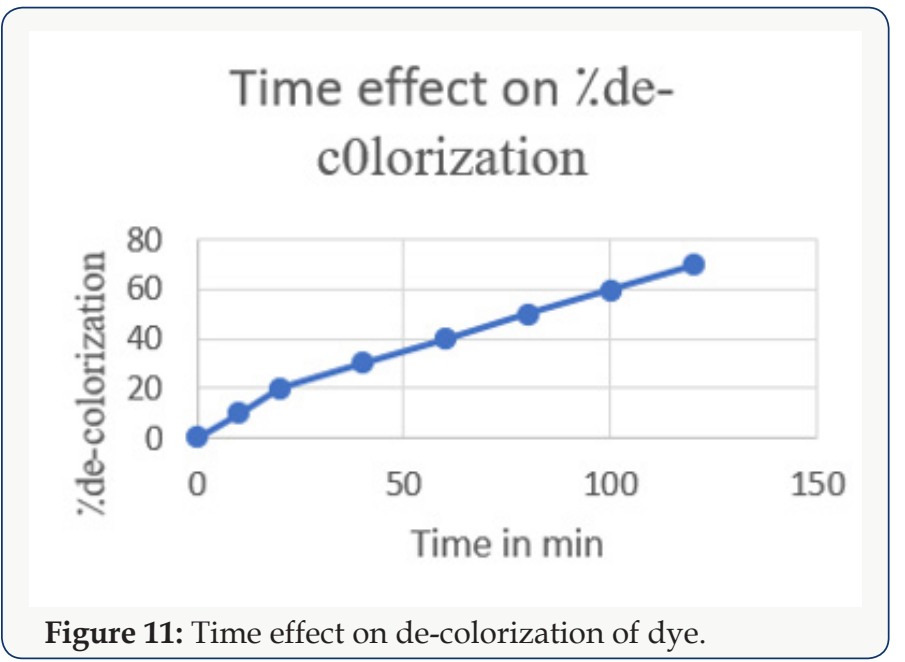

Citation: Madiha B, Zahid Q, Aliya B. Removal of Melachite Green Dye by Using Zinc Oxide Nanoparticles Prepared by The Green Synthesis by

Using Camellia Sinensis (Green Tea) Leafs Extract. Arch Nano Op Acc J 1(4). 2018. ANOAJ.MS.ID.000120. DOI: 10.32474/ANOAJ.2018.01.000120.

\section{Preparation of $1000 \mathrm{mg} / \mathrm{L}$ Dye S.S}

$1000 \mathrm{ppm}$ solution of malachite green was prepared by dissolving the dye in 1 litter distilled water. Different concentration of dyes was prepared for the stock solution. 100ppm solution was prepared from $1000 \mathrm{ppm}$ solution after dilution. After that 150 , 200, 250ppm solution was prepared. Color removal efficiency cab be calculated by the formula:

$\%$ decolorization $=\mathrm{abs}_{\mathrm{o}}-\mathrm{absf} / \mathrm{abs}_{\mathrm{o}} \times 100[12]$

\section{Melachite Green Dye}

Malachite green having chemical formula $\mathrm{C}_{2} 3 \mathrm{H}_{2} 5 \mathrm{CIN}_{2}$ (chloride) or $\left[\mathrm{C}_{6} \mathrm{H}_{5} \mathrm{C}\left(\mathrm{C}_{6} \mathrm{H}_{4} \mathrm{~N}\left(\mathrm{CH}_{3}\right)_{2}\right)_{2}\right] \mathrm{Cl}$ is normally used as a dye. It has a molar mass of $364.911 \mathrm{~g} / \mathrm{mol}$. The intense green color of the dye results from a strong absorption band at $621 \mathrm{~nm}$ in UV visible spectra. This dye is moderately toxic and extremely irritant [12]. (Figures $11 \& 12$ ).

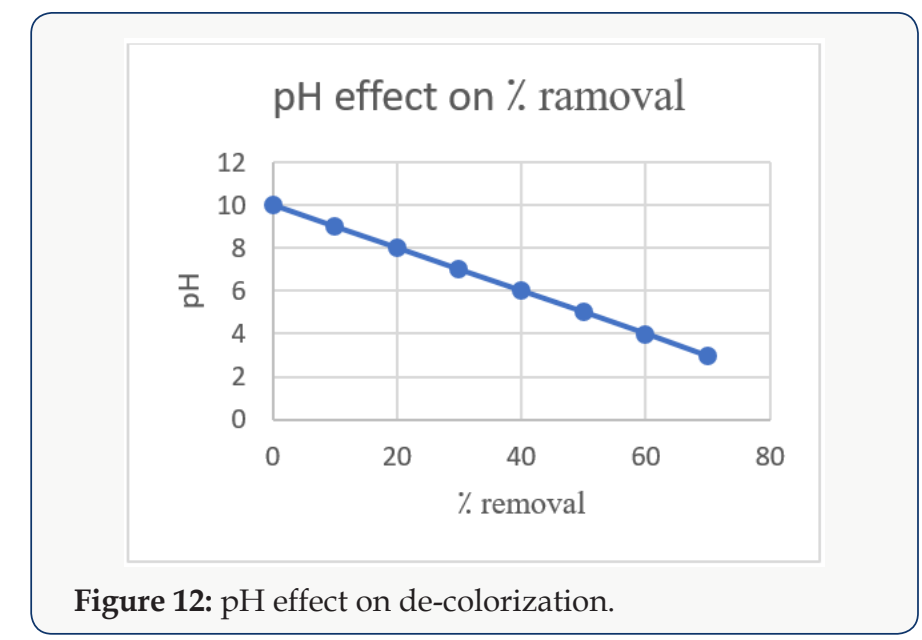

\section{Equilibrium Studies on De-Colorization}

\section{effect of dosage of dye on \%removal}

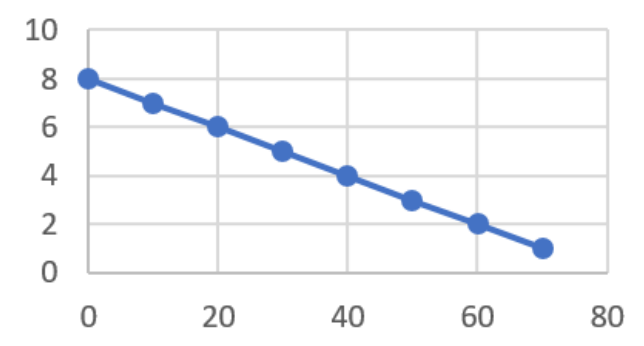

Figure 13: Conc. effect on dye removal.

Effect of Temperature: The de-colorization of dye was studied at room temperature. Initially the amount taken was $20 \mathrm{ml}$ of melachite green dye solution and about $1 \mathrm{mg}$ of zinc oxide nanoparticles synthesized by green tea. During the process the time intervals was noted gradually. The percentage removal of decolorization was calculated and then graph was plotted according to readings. The maximum time taken was $120 \mathrm{~min}$ with $70 \%$ color 
remove. This color removal confirms the rapid reaction of zinc (Figure 13).

$\mathbf{P}_{\mathrm{H}}$ Effect on Dye Removal: De-colorization of dye is strongly affected by $\mathbf{P}_{\mathbf{H}}$ of the solution. In this research we have studied the $\mathrm{PH}$ effect on decolorization of dye using zinc oxide nanoparticles. Zinc oxide nanoparticles showed a maximum de-colorization on increasing the $\mathbf{P}_{\mathbf{H}}$ but after a certain limit the more increase has a negative impact. This may happen due to the formation of more positive ions. Maximum de-colorization at $70 \%$ have the $\mathbf{P}_{\mathbf{H}}$ value of 3 .

\section{Concentration of Dye}

The concentration of dye plays an important role in the decolorization process. A graph was drawn after the experiment on different concentrations of dye. The maximum amount taken was $10 \mathrm{mg} / \mathrm{l}$. after increasing the concentration of dye effect on $70 \%$ decolorization of dye was observed.

\section{Effect of Concentration of Zinc Oxide Nanoparticles}

The amount of zinc oxide nanoparticles has a positive response to the de-colorization of dye. Firstly $1 \mathrm{mg} / \mathrm{l}$ was taken and after some time interval the color was removed which prove that further increase in zinc oxide nanoparticles concentration will not affect the de-colorization of dye? (Figure 14).

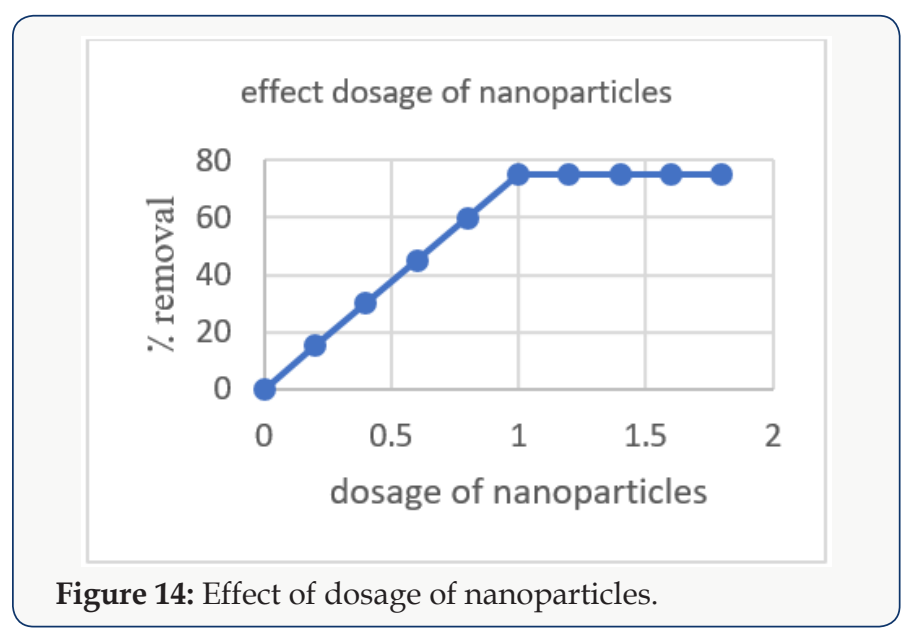

\section{Conclusion}

In conclusion here we report an eco-friendly, feasible and short time preparation of zinc oxide nanoparticles by leaf extract of green tea. This method has an advantage over other reported methods as it is easily available starting materials, not costly and the procedure is easy to handle in the laboratory, no toxic reagent is used and pollution free. UV spectra of prepared particles was tested in UV spectrophotometer which was $320 \mathrm{~nm}$. it shows the wavelength range of nanoparticles. Highest peak shows the maximum absorbance. FTIR spectra confirmed the presence of zinc oxide nanoparticles. Also, other peaks were obtained showing presence of other groups and their stretching and bending was also defined. XRD and SEM defined the shape and size of nanoparticles which was hexagonal and the size range was about 80-120nm. XRD confirmed the presence of both zinc and zinc oxide nanoparticles. The mineral name is zincite. Its common name is Chinese white. The space group is 186.the calculated density was $5.68 \mathrm{~g} / \mathrm{cm}^{3}$. and measured density was $5.66 \mathrm{~g} / \mathrm{cm}^{3}$. $<0.001 \%$ of each $\mathrm{Mg}$, Si, Ca were present. The temperature at which we collected data was $26^{\circ} \mathrm{C}$. An application of dye removal is of great importance which was performed by using malachite green dye. The green color of dye was removed using zinc oxide nanoparticles that were prepared by using green tea leaf extract. The effects of temperature, $\mathbf{P}_{\mathbf{H}^{\prime}}$ concentration of both the dye and nanoparticles on de-colorization was also studied. The maximum de-colorization obtained was $70 \%$ At the end the color was removed. When the color was removed by nanoparticles the last $\mathbf{P}_{\mathbf{H}}$ noted was 3 by using $\mathbf{P}_{\mathbf{H}}$ paper. Nanoparticles of zinc oxide synthesized can also be applicable in different field of biochemistry, medicine and industry.

\section{References}

1. Cumberland SA (2011) Synthesis and environmental chemistry of silver and iron oxide nanoparticles.

2. Sheldon RA (2012) Fundamentals of green chemistry: efficiency in reaction design. Chemical Society Reviews 41(4): 1437-1451.

3. Dauthal P, Mukhopadhyay M (2016) Noble metal nanoparticles: plantmediated synthesis, mechanistic aspects of synthesis, and applications. Industrial \& Engineering Chemistry Research 55(36): 9557-9577.

4. Gupta J, Siddique YH, Beg T, Ara G, Afzal M (2008) A review on the beneficial effects of tea polyphenols on human health. International Journal of Pharmacology 4(5): 314-338.

5. Hill SJ, Arowolo TA, Butler OT, Chenery SR, Cook JM, et al. (2002) Atomic spectrometry update. Environmental analysis. Journal of Analytical Atomic Spectrometry 17(3): 284-317.

6. Varghese E, George M, (2015) Green synthesis of Zinc oxide nanoparticles. International Journal of Advance Research in Science and Engineering 4(1): 307-314.

7. Yuvakkumar R, Suresh J, Hong SI (2014) Green synthesis of zinc oxide nanoparticles. In Advanced Materials Research 952: 137-140.

8. Kumar SSR (2017) Green Synthesis of Nanoparticles Using Plant Extracts and Their Effect on Rumen Fermentation in Vitro.

9. Meruvu H, Vangalapati M, Chippada SC, Bammidi SR (2011) Synthesis and characterization of zinc oxide nanoparticles and its antimicrobial activity against Bacillus subtilis and Escherichia coli. J Rasayan Chem 4(1): 217-222.

10. Koen Y (2010) Synthesis and investigation of smart nanoparticles (Doctoral dissertation, Stellenbosch: University of Stellenbosch).

11. Garg VK, Kumar R, Gupta R, (2004) Removal of malachite green dye from aqueous solution by adsorption using agro-industry waste: a case study of Prosopis cineraria. Dyes and Pigments 62(1): 1-10.

12. Kalantar-zadeh K, Fry B (2007) Nanotechnology-enabled sensors. Springer Science \& Business Media.

13. Graham HN (1992) Green tea composition, consumption, and polyphenol chemistry. Preventive medicine 21(3): 334-350.

14. Ghaedi M, Ansari A, Habibi MH, Asghari AR (2014) Removal of malachite green from aqueous solution by zinc oxide nanoparticle loaded on activated carbon: kinetics and isotherm study. Journal of Industrial and Engineering Chemistry 20(1): 17-28. 
(C) (P) This work is licensed under Creative

To Submit Your Article Click Here: Submit Article

DOI: $10.32474 /$ ANOAJ.2018.01.000120.

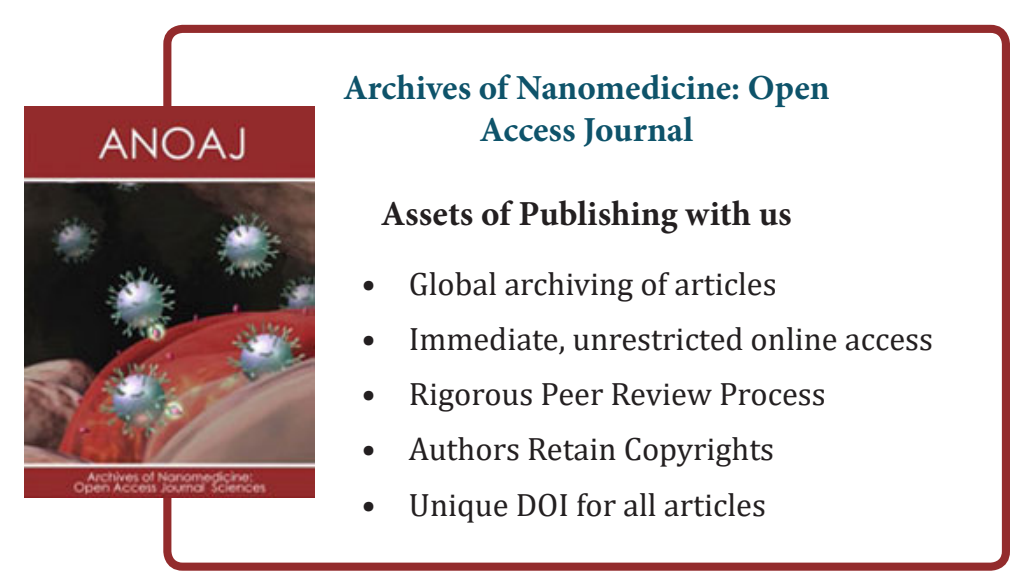

